\title{
The Neurodynamics of Epilepsy: Synaptic regulation and reversal potential modulation during seizures in a neural field model with conductance-based synapses
}

\author{
Andre D H Peterson 1,2,3* , Iven MY Mareels ${ }^{2}$, Hamish Meffin ${ }^{2,4}$, David B Grayden 1,2,5, Mark J Cook ${ }^{2,3}$, \\ Anthony N Burkitt ${ }^{1,2,5}$
}

From Twenty Second Annual Computational Neuroscience Meeting: CNS*2013

Paris, France. 13-18 July 2013

Recent experimental results have shown that during the initiation and termination of epileptic seizures there is a significant change in the micro-ionic environment of cortical neurons [1] that affects network balance between excitation and inhibition. This is evident through non-synaptic changes in the micro-ionic environment such as the excitatory and inhibitory reversal potentials and conductances that have been measured over the course of a seizure in an in vitro mouse model [2]. Although this phenomenon of a change in reversal potentials during seizures has recently been simulated numerically using a relatively small number of detailed multi-compartmental spiking models [3], it has not yet been modelled using larger scale mesoscopic neural field models within an analytical framework. This is because the majority of these models use current-based synapses, which do not take the reversal potentials into account [4] as they are more difficult to incorporate in mesoscopic models of brain dynamics.

We present an analysis of a neural field model with conductance-based synapses that takes into account the reversal potentials and the nonlinear multiplicative effect that they have on the associated conductance. The conductance-based synapses model is derived, analysed and juxtaposed with the current-based synapses model and the results interpreted physiologically.

A comparative bifurcation analysis of both models reveals that there are significant differences in the

\footnotetext{
*Correspondence: peterson@unimelb.edu.au

'NeuroEngineering Lab, Dept. of Electrical \& Electronic Engineering,

University of Melbourne, Australia

Full list of author information is available at the end of the article
}

oscillatory behaviours that correspond to epileptic seizures [4]. In the conductance-based synapses model, there are endogenous anti-epileptic regulatory or control mechanisms that operate on the synaptic scale, whereas previously these were thought to be mainly on the network level; for example, in terms of feedback, feedforward and surround inhibition [5]. Further, upon modulation of the reversal potentials, the new model exhibits seizure behaviour that initiates and terminates due to non-synaptic ionic mechanisms, similar to that measured in recent experiments [1].

Seizure dynamics in the brain are modulated by both synaptic regulatory mechanisms and non-synaptic homeostatic mechanisms, which play key roles during seizure initiation, spread and termination [5]. These mechanisms have been investigated using a novel analytical neural field model which has provided insights into understanding epileptic brain dynamics that are not currently observable in electrophysiological experiments and numerical simulations alone.

\section{Acknowledgements}

This work was supported by ARC Linkage Project \#LP0560684 and an SVHM REF grant.

\section{Author details}

${ }^{1}$ NeuroEngineering Lab, Dept. of Electrical \& Electronic Engineering, University of Melbourne, Australia. ${ }^{2}$ Centre for Neural Engineering, University of Melbourne, Australia. ${ }^{3}$ Centre for Clinical Neurosciences, St. Vincent's Hospital, Melbourne, Australia. ${ }^{4}$ NICTA Victoria Research Lab, Melbourne, Australia. ${ }^{5}$ Bionics Institute, East Melbourne, Australia.

Published: 8 July 2013 


\section{References}

1. Barmashenko G, Hefft S, Aertsen A, Kirschstein T, Köhling R: Positive shifts of the GABA-A receptor reversal potential due to altered chloride homeostasis is widespread after status epilepticus. Epilepsia 2011, 52(9):1570-1578

2. Ziburkus J, Cressman JR, Schiff S: Seizures as imbalanced up states: Excitatory and inhibitory conductances during seizure like events. J Neurophysiol 2012, doi:10.1152/jn.00232.2012

3. Krishnan GP, Bazhenov M: Ionic dynamics mediate spontaneous termination of seizures and postictal depression state. J Neurosci 2011, 31(24):8870-8882.

4. Breakspear M, Roberts JA, Terry JR, Rodrigues S, Mahant N, Robinson PA: A unifying explanation of primary generalized seizures through nonlinear brain modeling and bifurcation analysis. Cerebral Cortex 2006, 16(9):1296-1313.

5. Milton J, Jung P: Epilepsy as a Dynamic Disease. 2003, Springer.

doi:10.1186/1471-2202-14-S1-P47

Cite this article as: Peterson et al:: The Neurodynamics of Epilepsy: Synaptic regulation and reversal potential modulation during seizures in a neural field model with conductance-based synapses. BMC

Neuroscience 2013 14(Suppl 1):P47.

\section{Submit your next manuscript to BioMed Central} and take full advantage of:

- Convenient online submission

- Thorough peer review

- No space constraints or color figure charges

- Immediate publication on acceptance

- Inclusion in PubMed, CAS, Scopus and Google Scholar

- Research which is freely available for redistribution

Submit your manuscript at www.biomedcentral.com/submit 